\title{
Endoventricular spiral plication for ischemic dilated cardiomyopathy
}

\author{
Arudo Hiraoka, MD, Masahiko Kuinose, MD, Genta Chikazawa, MD, and Hidenori Yoshitaka, MD, \\ Okayama, Japan
}

Surgical reconstruction of the left ventricle (LV) has evolved, but it remains challenging. We have reported successful cases of a modified endoventricular plasty called "endoventricular spiral plication" (ESP), which is aimed at rebuilding both the physiologic shape and volume of the LV. ${ }^{1,2}$ We performed the ESP technique in 8 cases, and this brief communication reports the favorable results.

\section{CLINICAL SUMMARY}

Eight patients underwent the ESP technique in our institution between May 2010 and August 2011. All the patients were male, with a mean age of $62.1 \pm 9.8$ years

From the Department of Cardiovascular Surgery, The Sakakibara Heart Institute of Okayama, Okayama, Japan.

Disclosures: Authors have nothing to disclose with regard to commercial support. Received for publication Nov 28, 2011; revisions received Dec 16, 2011; accepted for publication Jan 4, 2012; available ahead of print Feb 1, 2012.

Address for reprints: Arudo Hiraoka, MD, Department of Cardiovascular Surgery,

The Sakakibara Heart Institute of Okayama, 2-1-10 Marunouchi, Okayama, 700-

0823, Japan (E-mail: bassbord1028@yahoo.co.jp).

J Thorac Cardiovasc Surg 2012;144:269-70

$0022-5223 / \$ 36.00$

Copyright (C) 2012 by The American Association for Thoracic Surgery doi:10.1016/j.jtcvs.2012.01.013 and an average body surface area of $1.69 \pm 0.19 \mathrm{~m}^{2}$. All patients had a history of previous anterior myocardial infarction. There were 3 patients in New York Heart Association (NYHA) functional class II, 4 patients in NYHA class III, and 1 patient in NYHA class IV (mean class $2.8 \pm 0.7)$. The average severity of preoperative mitral regurgitation was grade $2.1 \pm 1.0$, and all cases of mitral regurgitation were due to tethering of mitral valve leaflet. Measurements of preoperative LV end-diastolic volume index, LV end-systolic volume index (ESVI), and LV ejection fraction (EF) were $141.7 \pm 25.5 \mathrm{~mL} / \mathrm{m}^{2}, 106.3 \pm$ $25.6 \mathrm{~mL} / \mathrm{m}^{2}$, and $26.3 \% \pm 8.7 \%$, respectively, according to cardiac magnetic resonance imaging. The mean preoperative level of B-type natriuretic peptide was $853 \pm 529$ $\mathrm{pg} / \mathrm{mL}$.

Informed consent was obtained from all patients before the operation. After the LV was opened at the apex parallel to the left anterior descending artery, the boundaries between the normal and aneurysmal scar tissues were identified. Continuous double-spiral sutures with a pledgeted 3-0 polypropylene stitch were started at the origin of the papillary muscle for the papillary muscle approximation.

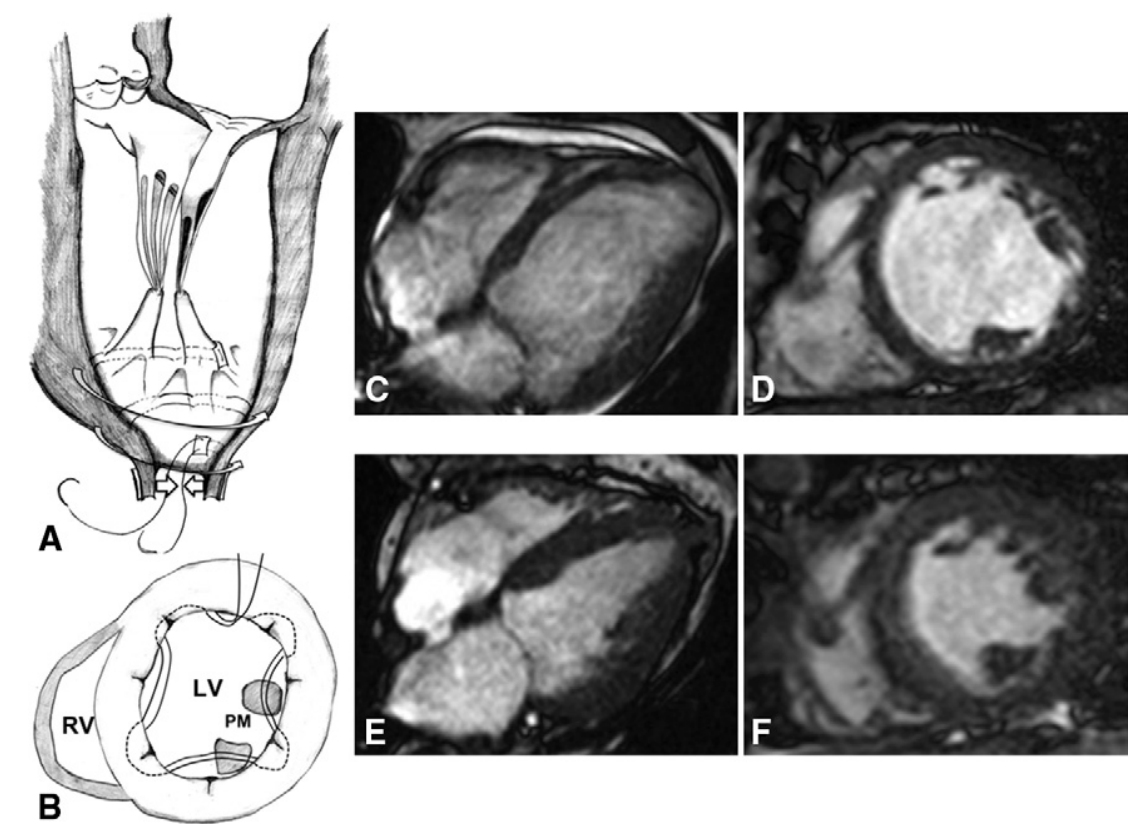

FIGURE 1. A and B, Endoventricular spiral plication technique schema. A, Pledgeted suture was started and sewn spirally to the end of scar tissue, rotating in a clockwise direction. The remaining opening of the ventricle could be closed directly without any patch material. B, Illustration of the spiral stitches gathering the wall of the left ventricle $(L V)$ and reducing the distance between the papillary muscles $(P M)$. C through F: Comparison of the preoperative long- and short-axis magnetic resonance images $(\mathrm{C}$ and $\mathrm{D}$, respectively) with their respective postoperative images $(\mathrm{E}$ and $\mathrm{F})$. The well-restored volume, shape, and thickness of the left ventricular wall is revealed. $R V$, Right ventricle. 
TABLE 1. Comparison between the preoperative and postoperative patient data

\begin{tabular}{lccc}
\hline & Preoperative & Postoperative & $P$ value \\
\hline Magnetic resonance imaging & & 3 mo & \\
LV ejection fraction $(\%)$ & $26.3 \% \pm 8.7 \%$ & $31.8 \% \pm 8.0 \%$ & NS \\
LV end-diastolic volume $\left(\mathrm{mL} / \mathrm{m}^{2}\right)$ & $141.7 \pm 25.5$ & $92.4 \pm 22.4$ & $<.001$ \\
LV end-systolic volume $\left(\mathrm{mL} / \mathrm{m}^{2}\right)$ & $106.3 \pm 25.6$ & $62.8 \pm 16.3$ & $<.001$ \\
Transthoracic echocardiography & & $8.3 \pm 2.7 \mathrm{mo}$ & .006 \\
LV ejection fraction (\%) & $25.6 \% \pm 7.7 \%$ & $42.1 \% \pm 10.9 \%$ & .008 \\
LV end-diastolic dimension $(\mathrm{mm})$ & $62.8 \pm 3.5$ & $54.6 \pm 6.1$ & .005 \\
Mitral regurgitation $(0-4)$ & $2.1 \pm 1.0$ & $0.9 \pm 0.6$ & .01 \\
B-type natriuretic peptide $(\mathrm{pg} / \mathrm{mL})$ & $853 \pm 529$ & $192 \pm 182$ & \\
New York Heart Association functional class & $2.8 \pm 0.7$ & $1.1 \pm 0.4$ & $<.001$ \\
\hline
\end{tabular}

All values are mean $\pm \mathrm{SD}$. $L V$, Left ventricular; $N S$, not significant.

If the boundaries between the normal and scar tissues did not extend to the origin of the papillary muscles, we used the ESP procedure and papillary muscle approximation, individually. Stitches were placed spirally at $2-\mathrm{cm}$ intervals, rotating in a clockwise direction between the basal septum and the newly created LV apex to plicate or reduce LV volume. The remaining opening of the ventricle could be closed without any patch material (Figure 1). Concomitant procedures included mitral valve annuloplasty in 6 cases, aortic valve replacement in 1 case, tricuspid valve annuloplasty in 1 case, and coronary artery bypass grafting $(\mathrm{CABG})$ in all cases.

\section{RESULTS}

Although there was 1 patient with a subdural hematoma, he had a successful recovery after craniotomy. The other 7 patients had uneventful recoveries, and all patients were followed up for $367 \pm 159$ days. There was 1 patient in NYHA functional class II; the remaining 7 patients were in NYHA functional class I $(1.1 \pm 0.4)$. At 3 months after surgery, cardiac magnetic resonance imaging showed a nicely reconstructed physiologic shape and volume of the LV, and LV end-diastolic volume index and LV ESVI were decreased to $92.4 \pm 22.4 \mathrm{~mL} / \mathrm{m}^{2}(P<.001)$ and $62.8 \pm 16.3 \mathrm{~mL} / \mathrm{m}^{2}$ $(P<.001$; Figure 1), respectively. The percentage of reduction in LV ESVI was $39.9 \% \pm 13.5 \%$. Postoperative follow-up transthoracic echocardiography $(8.3 \pm 2.7$ months after surgery) revealed improvements in LV dimension, LV function, and mitral regurgitation. LV end-diastolic dimension was $54.6 \pm 6.1 \mathrm{~mm}$ (vs $62.8 \pm 3.5 \mathrm{~mm}$ preoperative $\mathrm{LV}$ end-diastolic dimension; $P=.008$ ), and LV EF was $42.1 \% \pm 10.9 \%$ (vs $25.6 \pm 7.7 \%$ preoperative LV EF; $P=.006$ ). The mean level of postoperative B-type natriuretic peptide decreased to $192 \pm 182 \mathrm{pg} / \mathrm{mL}(P=.01$; Table 1$)$.

\section{DISCUSSION}

Surgical ventricular restoration for ischemic dilated cardiomyopathy has been evolving, but the results of the
Surgical Treatment for Ischemic Heart Failure trial showed no differences in survival between CABG alone and CABG plus surgical ventricular restoration. ${ }^{3}$ The purpose of the surgical ventricular restoration in the Surgical Treatment for Ischemic Heart Failure trial was volume reduction and not shape reconstruction of the LV; however, only a $19 \%$ reduction of LV ESVI (from 83 to $67 \mathrm{~mL} / \mathrm{m}^{2}$ ) could be achieved in the study, regardless of the $40 \%$ volume reduction needed. ${ }^{4}$ Additionally, the importance for cardiac function and survival of the anatomic shape rather than ideal LV volume has been emphasized. ${ }^{5}$ Our ESP technique was aimed at restoration of both the shape and volume with minimum ventriculectomy, and we achieved $39.9 \% \pm 13.5 \%$ reduction in LV ESVI with conical shape preservation. Postoperative LV EF, as measured by magnetic resonance imaging, did not significantly increase; however, postoperative echocardiography did show significant improvement in LV EF. This may have been due to late remodeling of the LV. Although the outcomes of the ESP technique were quite satisfactory, the drastic improvement in patient condition may have resulted from concomitant CABG and mitral valve annuloplasty. In conclusion, although the results of the ESP technique are acceptable, long-term follow-up is crucial to determine the benefits of respective interventions.

\section{References}

1. Hiraoka A, Kuinose M, Chikazawa G, Yoshitaka H. A modified technique of left ventricular restoration: endoventricular spiral plication. J Card Surg. 2011;26: 261-3.

2. Hiraoka A, Kuinose M, Chikazawa G, Totsugawa T, Katayama K, Yoshitaka H. Review of 6 cases of modified left ventricular restoration: endoventricular spiral plication. Chirurgia. 2012. In press.

3. Jones RH, Velazquez EJ, Michler RE, Sopko G, Oh JK, O'Connor CM, et al. Coronary bypass surgery with or without surgical ventricular reconstruction. $\mathrm{N} \mathrm{Engl}$ J Med. 2009;360:1705-17.

4. Buckberg GD, Athanasuleas CL. The STICH trial: misguided conclusions. J Thorac Cardiovasc Surg. 2009;138:1060-1064.e2.

5. Buckberg GD. Basic science review: the helix and the heart. J Thorac Cardiovasc Surg. 2002;124:863-83. 